(4 



\section{Das Entropieprinzip}

Thermodynamik für Unzufriedene

von

Prof.Dr. André Thess 
Prof. Dr. André Thess arbeitet als Professor für Thermodynamik und Magnetofluiddynamik an der Technischen Universität Ilmenau. Forschungsaufenthalte und Gastprofessuren führten ihn unter anderem an die Universitäten Princeton, Stanford, Michigan (USA), ENS Lyon, Ecole Polytechnique (Frankreich), Nagoya (Japan) und Shenyang (China). Seine Forschungsinteressen reichen von der elektromagnetischen Strömungsmessung in flüssigem Stahl bis zur Turbulenzforschung am weltgrößten Rayleigh-Bénard-Experiment „Ilmenauer Fass“, welches unter seiner Leitung erbaut wurde.

Bibliografische Information der Deutschen Nationalbibliothek

Die Deutsche Nationalbibliothek verzeichnet diese Publikation in der Deutschen Nationalbibliografie; detaillierte bibliografische Daten sind im Internet über $<$ http://dnb.d-nb.de> abrufbar.

(C) 2007 Oldenbourg Wissenschaftsverlag GmbH

Rosenheimer Straße 145, D-81671 München

Telefon: (089) 45051-0

oldenbourg.de

Das Werk einschließlich aller Abbildungen ist urheberrechtlich geschützt. Jede Verwertung außerhalb der Grenzen des Urheberrechtsgesetzes ist ohne Zustimmung des Verlages unzulässig und strafbar. Das gilt insbesondere für Vervielfältigungen, Übersetzungen, Mikroverfilmungen und die Einspeicherung und Bearbeitung in elektronischen Systemen.

Lektorat: Anton Schmid

Herstellung: Anna Grosser

Coverentwurf: Kochan \& Partner, München

Gedruckt auf säure- und chlorfreiem Papier

Druck: Grafik + Druck, München

Bindung: Thomas Buchbinderei GmbH, Augsburg

ISBN 978-3-486-58428-8 